\title{
Developmental trajectories of reading development and impairment from ages 3 to 8 years in Chinese children
}

\author{
Lin Lei, ${ }^{1,6}$ Jinger Pan, ${ }^{1}$ Hongyun Liu, ${ }^{2}$ Catherine McBride-Chang, ${ }^{3}$ Hong $\mathrm{Li}^{2}$ \\ Yuping Zhang, ${ }^{1}$ Lang Chen, ${ }^{1,7}$ Twila Tardif, ${ }^{4}$ Weilan Liang, ${ }^{5}$ Zhixiang Zhang, \\ and Hua Shu ${ }^{1}$ \\ ${ }^{1}$ State Key Laboratory of Cognitive Neuroscience and Learning, Beijing Normal University, China; ${ }^{2}$ School of \\ Psychology, Beijing Normal University, China; ${ }^{3}$ Department of Psychology, The Chinese University of Hong Kong, \\ Hong Kong; ${ }^{4}$ Department of Psychology and Center for Human Growth and Development, University of Michigan-Ann \\ Arbor, USA; ${ }^{5}$ Peking University First Hospital, China; ${ }^{6}$ School of Political Science and Public Administration, \\ University of Electronic Science and Technology, China; ${ }^{7}$ Department of Psychology, University of \\ Wisconsin-Madison, USA
}

\begin{abstract}
Background: Early prediction of reading disabilities in Chinese is important for early remediation efforts. In this 6-year longitudinal study, we investigated the early cognitive predictors of reading skill in a statistically representative sample of Chinese children from Beijing. Method: Two hundred sixty-one (261) native Chinese children were administered seven language-related skills over three years between the ages of 3 and 6 years. Performances on these skills were then examined in relation to subsequent word reading accuracy and fluency. Individual differences in developmental profiles across tasks were then estimated using growth mixture modeling. Results: Four developmental trajectories were classified - the typical (control), catch-up (with low initial cognitive performances but adequate subsequent reading), literacy-related-cognitive-delay (with difficulties in morphological awareness, phonological awareness, and speeded naming and subsequent word recognition), and language-delay (relatively low across all tasks) groups. Conclusion: Findings suggest that the combination of phonological awareness, rapid naming and morphological awareness are essential in the early prediction of later reading difficulties in Chinese children. Keywords: Morphological awareness, grammar, vocabulary knowledge, phonological awareness, rapid automatized naming (RAN).
\end{abstract}

Early identification of children with dyslexia is important because remediation efforts are often maximized in young children (Gabrieli, 2009). For example, growth modeling of data across a 10-year longitudinal study demonstrated that Finnish children's later reading difficulties could be attributed to phonological awareness, rapid automatized naming (RAN), and/or letter knowledge in the early years (Lyytinen et al., 2006); these skills are now routinely targeted in young Finnish children in order to remediate potential reading difficulties early. The present study focused on two main questions. First, what are the best longitudinal predictors of reading difficulties in Chinese children? Second, and more generally, what is the nature of reading development across children manifesting different early cognitive and linguistic profiles?

A number of skills, including phonological processing, vocabulary knowledge, and morphology, have all been found to be significantly correlated with Chinese reading. Phonological processing deficits tend to be a universal marker of reading diffi-

Conflict of interest statement: No conflicts declared. culties (e.g., Bradley \& Bryant, 1981; Ziegler et al., 2010). These include phonological awareness (Torgesen, Wagner, Rashotte, Burgess, \& Hecht, 1997; Shu, McBride-Chang, Wu, \& Liu, 2006), phonological memory (Ho, Chan, Lee, Tsang, \& Luan, 2004; Siegel \& Ryan, 1989), and RAN (e.g., Torgesen, et al., 1997; Shu et al., 2006). Vocabulary knowledge (e.g., Viholainen et al., 2006) and grammatical skill (Tager-Flusberg \& Cooper, 1999) may also be linked to risk for dyslexia, as they are for language-delay. In Chinese, as in alphabetic orthographies, a large proportion of children with early language problems also manifest subsequent dyslexia (Wong, Kidd, Ho, $\& \mathrm{Au}, 2010)$. Moreover, early expressive vocabulary knowledge and grammatical skills predicted subsequent word recognition performance in one study of Hong Kong Chinese children (Liu et al., 2010). Furthermore, lexical compounding has also been linked to dyslexia in young Chinese children (e.g., McBride-Chang et al., in press, 2008; Wong et al., 2010).

Chinese children with dyslexia sometimes manifest multi-deficits (e.g. Ho et al., 2004). This phenomenon of multi-deficits might be attributable to the fact that orthography, phonology and meaning 
are particularly densely packed in Chinese singleword reading. In the present study, simultaneous deficits in phonological awareness, rapid naming and morphological awareness were hypothesized to form the 'core' predictors of reading difficulties, as they have in various combinations in previous studies of developmental dyslexia in Chinese (e.g., Chung et al., 2008; McBride-Chang et al., in press; Shu et al., 2006; Wong et al., 2010). At the same time, however, we also expected to observe a separate group of children who might be characterized as more generally language impaired. Previous studies have demonstrated that language impaired Chinese children tend to manifest a fairly wide range of reading-related difficulties (e.g., McBrideChang et al., 2008; Wong et al., 2010). These children tend to be more globally impaired than those with specific reading difficulties (e.g., Bishop \& Snowling, 2004).

Apart from the commonly recognized reading disabled and language delayed groups of children (e.g., Bishop \& Snowling, 2004; Wong et al., 2010) across societies, we questioned whether any other developmental trajectories of literacy acquisition would emerge in our representative sample. Family environment (e.g., Hecht, Burgess, Torgesen, Wagner, \& Rashotte, 2000), particularly focused on low parental education levels (e.g., Rauh, Parker, Garfinkel, Perry, \& Andrews, 2003), has been implicated in reading difficulties in some children. Thus in the present study, we examined mothers' educational levels in relation to children's developmental trajectories for reading development. Following previous work demonstrating the unique association of socioeconomic status to reading performance from kindergarten to third grade in American children (Hecht et al., 2000), we hypothesized that children from families with relatively low levels of education would show sustained reading difficulties over time.

To summarize, we used a variety of early linguistic tasks administered at ages 3 to 6 years to identify developmental trajectories leading to reading difficulties in Chinese children at age 8 years. We expected to find a group of reading disabled children, for whom simultaneous deficits in phonological awareness, rapid naming, and morphological awareness would emerge, and another group of more generally language impaired children. We also tested the extent to which parental background influenced reading acquisition trajectories. Latent growth mixture modeling allowed us to identify groups with particular characteristics related to metalinguistic skills and to test for changes in development. For example, children with higher initial cognitive skill levels tend to demonstrate faster growth rates in some studies (Scarborough \& Parker, 2003), but not others (Leppänen, Niemi, Aunola, \& Nurmi, 2004). This technique affords the opportunity to examine development with respect to a number of potentially critical variables simultaneously.

\section{Method}

\section{Participants}

This study reports on linguistic predictors measured at ages 3.4 to 6.4 years and literacy skills at age 8.4 years for 261 Chinese children (142 boys and 119 girls) who were living in Beijing and were part of a larger group of 1,638 children who were initially selected to be demographically representative of the city so as to develop the Putonghua version of the Communicative Development Inventory (CDI) in 2000 (Tardif, Fletcher, Zhang, \& Liang, 2008). The children in the present follow-up study were a subset of that large sample, selected to represent the top, middle, and bottom range of scores on the CDI (Putonghua version) infant and toddler forms. All the children were tested 4 times across approximately 12month intervals from ages 3.4 to 6.4 years; ages at which each task was administered are shown in Table 1.

\section{Measures}

Compound awareness. In this receptive task, children were presented with four pictures per item as the experimenter orally named the pseudoword that the child was asked to identify. For example, given the pseudoword '袋鼠' (i.e., bag-cat, a nonexistent animal analogous to '袋猫' (i.e., bag-mouse, which means kangaroo in Chinese), and four pictures, i.e., A) bag-mouse B) eagle with a dog head, C) cat, and D) bag-cat, the selection of D is correct.

Grammatical skills. Loosely based on Bishop's (1979) Test for Reception of Grammar (TROG), children were orally presented with a phrase or sentence such as 'three flowers', along with four visually presented pictures (e.g., one flower, three trees, one dog, three flowers) that were not verbally labeled and asked to select the correct one.

Nonword repetition. In this task, children were asked to repeat nonsense syllables that were orally presented by the experimenter. Trials ranged in order of difficulty from one- to four-syllable nonwords. The test was similar to one administered by Stokes, Wong, Fletcher, and Leonard (2006) and Liu et al. (2009) in Cantonese.

Syllable deletion. Following previous work (e.g., Chen, Hao, Geva, Zhu, \& Shu, 2009), in this task, children were asked to say a word with a given syllable omitted in a phrase of two or three syllables. For instance, children were asked to say /qi4 che1 zhan4/ (bus station) without /zhan4/ (the correct answer is /qi4 che1/ (vehicle)).

Morphological construction. This task, which has been used in previous studies (e.g., McBride-Chang, Shu, Zhou, Wat, \& Wagner, 2003), requires children to combine known morphemes in new ways using lexical compounding. For example, a tree that grows shoes could be called a shoe tree.

Rapid automatized naming (RAN). RAN was tested at age 4 using an object-naming task consisting of 5 different 2-syllable pictured objects (e.g., monkey). Because digit-naming is quite easy for young Chinese 
Table 1 Raw means, standard deviations, reliabilities, skewness, and kurtosis of different tasks

\begin{tabular}{|c|c|c|c|c|c|c|c|}
\hline & Max & Age (SD) & M (SD) & Range & Skewness & Kurtosis & Reliability (alpha) \\
\hline \multirow[t]{3}{*}{ Compound awareness } & 16 & $3.4(.27)$ & $8.72(2.57)$ & $0-15$ & .03 & .45 & .49 \\
\hline & 16 & $4.4(.28)$ & $11.00(2.58)$ & $3-16$ & -.57 & -.13 & .58 \\
\hline & 24 & $5.4(.28)$ & $20.69(2.41)$ & $13-24$ & -1.02 & .69 & .58 \\
\hline \multirow[t]{3}{*}{ Grammatical skills } & 86 & $3.4(.27)$ & $59.58(12.18)$ & $0-80$ & -1.40 & 3.00 & .91 \\
\hline & 78 & $4.4(.28)$ & $62.16(6.91)$ & $26-75$ & -.42 & -.40 & .80 \\
\hline & 36 & $5.4(.28)$ & $29.74(3.92)$ & $18-36$ & -.76 & .27 & .72 \\
\hline \multirow{2}{*}{ Nonword repetition } & 24 & $4.4(.28)$ & $16.50(4.33)$ & $0-24$ & -.81 & .55 & .80 \\
\hline & 24 & $5.4(.28)$ & $19.08(3.53)$ & $0-24$ & -1.38 & 3.45 & .77 \\
\hline \multirow[t]{3}{*}{ Syllable deletion } & 15 & $4.4(.28)$ & 8.15 (4.83) & $0-15$ & -.44 & -1.11 & .97 \\
\hline & 15 & $5.4(.28)$ & $11.95(3.04)$ & $0-15$ & -1.50 & 2.51 & .85 \\
\hline & 16 & $6.4(.27)$ & $14.03(2.89)$ & $2-16$ & -1.89 & 3.28 & .86 \\
\hline \multirow{3}{*}{$\begin{array}{l}\text { Morphological } \\
\text { construction }\end{array}$} & 15 & $4.4(.28)$ & $10.17(3.23)$ & $0-15$ & -1.21 & 1.42 & .82 \\
\hline & 18 & $5.4(.28)$ & $11.52(3.22)$ & $1-18$ & -.56 & .16 & .75 \\
\hline & 17 & $6.4(.27)$ & $10.66(3.24)$ & $0-17$ & -.49 & .52 & .73 \\
\hline \multirow{2}{*}{$\begin{array}{l}\text { Rapid automatized } \\
\text { naming }\end{array}$} & 25 (items) & $5.4(.28)$ & $23.03(7.52)$ & $9.41-42.13$ & .93 & 1.07 & - \\
\hline & 25 (items) & $6.4(.27)$ & $17.17(5.28)$ & $7.49-36.78$ & .98 & 1.19 & - \\
\hline \multirow[t]{3}{*}{ Vocabulary definition } & 64 & $4.4(.28)$ & $6.13(3.63)$ & $0-19$ & .50 & -.18 & .58 \\
\hline & 64 & $5.4(.28)$ & $7.98(4.00)$ & $0-19$ & .18 & -.38 & .68 \\
\hline & 64 & $6.4(.27)$ & $13.71(3.87)$ & $3-27$ & -.08 & .43 & .64 \\
\hline Character recognition & 150 & $8.4(.27)$ & $88.48(17.55)$ & $36-133$ & .28 & -.19 & .96 \\
\hline Reading fluency & 2505 & $8.4(.27)$ & 510.15 (228.97) & 84-1399 & 1.22 & 1.48 & .96 \\
\hline Nonverbal IQ & 24 & $4.4(.27)$ & $10.29(2.46)$ & $5-21$ & .82 & 1.64 & .53 \\
\hline
\end{tabular}

Note: All data are reported from all 261 children except for age 5 rapid naming, since there was one extreme value (82.60 seconds); thus only 260 children's data were included for this measure.

children (Zhou et al., 2007), and it has better predictability for reading than object-naming (Vaessen, Gerretsen, \& Blomert, 2009), a digit-naming task consisting of 5 different single digits $(1,3,4,5$, and 8$)$ was used at ages 5 and 6 . Across RAN tasks, children were asked to name the stimuli as correctly and rapidly as possible. Scores were calculated in seconds.

Vocabulary definitions. In this task, adapted from the Stanford-Binet Intelligence Scale vocabulary subtest (Thorndike, Hagen, \& Sattler, 1986) for Mandarin Chinese-speaking children, children were orally presented with a word and asked to give a definition of it.

Nonverbal IQ. Nonverbal IQ was measured using Raven's Standard Progressive Matrices (Raven, Court, $\&$ Raven, 1996) at age 4 only. Only the first two sets (A and B) were administered at this time.

Mother's education level. This was assessed among mothers of the participants using a seven-point selfreport scale, from 1 = lower than third grade, 2 = fourth to sixth grade, $3=$ junior high school completion, $4=$ senior high school completion, $5=$ college $6=$ university graduate, to $7=$ graduate school .

Character recognition. This task comprised 150 characters, all of which were expected to have been learned by grade 6 in Beijing (Shu, Chen, Anderson, Wu, \& Xuan, 2003).

Reading fluency. The reading fluency task was a timed task, following the procedures of Moll, Fussenegger, Willburger, and Landerl (2009). Children were given 3 minutes in which to read as many sentences as possible and indicate for each with ' $V$ ' or ' $x$ ' whether or not the sentence was correct. There are 90 sentences, increasing in length across the test. The dependent variable for this task is the sum of characters in the sentences with correct responses in 3 minutes.

The descriptive information for each task is presented in Table 1.

\section{Statistical approach}

In order to investigate the latent heterogeneous patterns of individuals' developmental trajectories, growth mixture modeling (Boscardin, Muthén, Francis, \& Baker, 2008; Lyytinen et al., 2006) from the MPLUS (version 3) program (Muthén \& Muthén, 2004) was used to analyze the repeated variables of the seven skill domains simultaneously. Because age differences even spanning a few months in early childhood might affect performance, we used $z$-scores computed within each age group for the linguistic and literacy measures in the following analyses. Age groups were defined separately each year according to actual age on the testing day; a three-month period was the range for a given group.

Growth mixture modeling distinguishes heterogeneous development subgroups in the population through use of categorical latent variables (Muthén, 2001). These latent variables represent different developmental trajectory groups. Individuals are inferred to be in one of the latent classes by the model. Within each class, individual developmental profiles are allowed to vary around the trajectory of this class. Figure 1 demonstrates the concept of the model for a single predictor. Since the predictors were measured successively across three times, there were three measurements for each task (indicated as first, second, and third measurements in Figure 1). Development was represented by Intercept and Growth, and groups' 


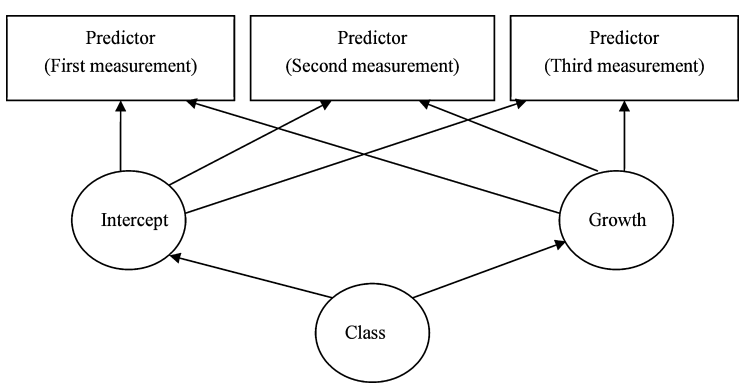

Figure 1 Path paradigm of the growth mixture model for the present study

classes were represented as latent variable Class; they were classified according to the values of Intercepts and Growths.

We included mixtures of multivariate growth models, where the simultaneous growth processes of seven skills were incorporated. In multivariate growth mixture modeling, variations of intercepts and slopes of the seven variables in the $K$ trajectory classes are allowed. This is important when we determine latent classes' numbers. Values of model fit criteria were obtained depending on how the degree of class invariance was specified.

\section{Model selection and model fit}

In growth mixture modeling, the model selection procedure is important since it determines the optimal number of classes that best represents the data. The statistical indices that are usually considered in determining which model to select are BIC and Entropy (Boscardin et al., 2008). BIC was used to compare model fit across non-nested models. The smaller the BIC value, the better the model fits the data. For a reliable classification of a subgroup, entropy indices should be between .90 and 1 .

\section{Results}

Correlations of the seven predictors and the reading outcome are shown in Table 2. Age correlated with the predictors significantly in most cases, and the seven predictors correlated significantly with literacy skills at age 8 , suggesting that these variables are sensitive to subsequent literacy skills.

Models with between two and six classes were fit to our longitudinal data. Results showed that the four-class model had the lowest BIC value, and the entropy value was closest to 1 . Thus, the four-class model best represented our data. The average latent class probabilities of individual membership in the class that the model selected were higher than .95, indicating that the four-class solution provided a good separation.

The means and standard deviations for each measure at different time points for the four trajectories (which we subsequently named, respectively, typical trajectory, catch-up trajectory, literacy-related-cognitive-delay trajectory (LRC-delay trajectory) and language-delay trajectory) are shown in Table 3. Most of the linguistic skills (except for syllable deletion, which was relatively high) and the final reading outcomes were approximately average (see Table 3) for the group of 184 children (about $70.5 \%$ ) referred to as showing a developmentally typical trajectory. We used this group as a standard for comparison with the three other trajectory groups.

Figure 2A shows the differences in intercepts and slopes of each skill between the typical and catch-up groups. The catch-up group of 31 children (11.9\%) differed from the typical one primarily only in syllable deletion and morphological construction but not in subsequent literacy skills. In contrast, the LRC-delay group of 32 children (12.3\%) was significantly behind in syllable deletion, morphological construction, and rapid naming (see Figure 2B), as well as both literacy skills, as compared to the typical group. Finally, the language-delay group of 14 children (5.4\%) showed comparative deficits across virtually all language skills at different points in development as well as both literacy skills at age 8 , as shown in Table 3 and Figure $2 \mathrm{C}$. These results suggest that a combination of syllable deletion, morphological construction, and rapid naming is important for early prediction; such findings are in accord with the results of simple correlation analyses, demonstrating relatively high associations of these three skills, as compared with the others, to reading (see Table 2).

In additional analyses, 4 out of 14 in the languagedelay but only 4 out of 32 in the LRC-delay children scored in the lowest $10 \%$ in character recognition, an untimed task. Similarly, 6 out of 14 in the languagedelay but 5 out of 32 in the LRC-delay group scored in the lowest $10 \%$ on reading fluency. Though a chisquare test was not significant between the two groups for character recognition: $\chi^{2}(1)=1.75$, $p=.19$, it showed a trend for reading fluency: $\chi^{2}(1)=3.96, p=.04$, suggesting that some of those with the greatest numbers of linguistic difficulties manifested the most severe reading deficits.

As Table 3 shows, the four groups did not differ significantly from one another in nonverbal IQ; neither did they differ in age across measurement points (for age $3, F(3,257)=1.28, p>.10$; for age 4 : $F(3,257)=1.27, p>.10$; for age $5: F(3,257)=.96$, $p>.10$; for age $6: F(3,257)=1.40, p>.10$; and for age 8: $F(3,257)=1.12, p>.10)$. However, though mother's educational level was not a significant predictor of subgroup classification, the mothers of children classified into the catch-up trajectory were significantly lower in educational level than were mothers of the typical one overall.

\section{Discussion}

Growth mixture modeling suggested at least four different developmental trajectories for young Chinese children with respect to reading difficulties in the present study. Typically developing children formed the largest (control) group. The catch-up 
Table 2 Correlations among the seven predictors at different measurement points and literacy skills at age 8

\begin{tabular}{|c|c|c|c|c|c|c|c|c|c|}
\hline & 1 & 2 & 3 & 4 & 5 & 6 & 7 & 8 & 9 \\
\hline \multicolumn{10}{|c|}{ Correlations among age 3 predictors and age 8 literacy skills } \\
\hline 1 Age-3 & - & & & & & & & & \\
\hline 2 CA-3 & $.17^{* *}$ & - & & & & & & & \\
\hline 3 GS-3 & $.28^{* *}$ & $.49 * *$ & - & & & & & & \\
\hline 4 NR-3 & $.29 * *$ & .14 & $.28 * *$ & - & & & & & \\
\hline $5 \mathrm{CR}-8$ & $.15^{*}$ & .14 & $.18^{* *}$ & $.26^{* *}$ & - & & & & \\
\hline $6 \mathrm{RF}-8$ & .09 & .09 & $.15^{*}$ & $.19 * *$ & $.66^{* *}$ & - & & & \\
\hline \multicolumn{10}{|c|}{ Correlations among age 4 predictors and age 8 literacy skills } \\
\hline 1 Age-4 & - & & & & & & & & \\
\hline $2 \mathrm{CA}-4$ & $.21^{* *}$ & - & & & & & & & \\
\hline 3 GS-4 & $.24^{* *}$ & $.51^{* *}$ & - & & & & & & \\
\hline 4 NR-4 & $.30^{* *}$ & $.30 * *$ & $.33^{* *}$ & - & & & & & \\
\hline $5 \mathrm{SD}-4$ & $.24^{* *}$ & $.19 * *$ & $.31^{* *}$ & $.37^{* *}$ & - & & & & \\
\hline $6 \mathrm{MC}-4$ & $.19 * *$ & $.34 * *$ & $.44 * *$ & $.38^{* *}$ & $.59 * *$ & - & & & \\
\hline $7 \mathrm{RN}-4$ & $-.15^{*}$ & $-.27 * *$ & -.29 ** & $-.28^{* *}$ & $-.33^{* *}$ & $-.42^{* *}$ & - & & \\
\hline $8 \mathrm{VD}-4$ & $.20^{* *}$ & $.29 * *$ & $.33^{* *}$ & $.25^{* *}$ & $.31^{* *}$ & $.47^{* *}$ & $-.40^{* *}$ & - & \\
\hline $9 \mathrm{CR}-8$ & $.15^{*}$ & $.25^{* *}$ & $.22^{* *}$ & $.26^{* *}$ & $.35^{* *}$ & $.31^{* *}$ & $-.27^{* *}$ & $.29 * *$ & - \\
\hline $10 \mathrm{RF}-8$ & .10 & $.17^{* *}$ & $.17^{* *}$ & $.18^{* *}$ & $.32^{* *}$ & $.29 * *$ & $-.40^{* *}$ & $.37^{* *}$ & $.67^{* * *}$ \\
\hline \multicolumn{10}{|c|}{ Correlations among age 5 predictors and age 8 literacy skills } \\
\hline 1 Age- 5 & - & & & & & & & & \\
\hline 2 CA-5 & $.16^{*}$ & - & & & & & & & \\
\hline 3 GS-5 & $.18^{* *}$ & $.56^{* *}$ & - & & & & & & \\
\hline 4 NR-5 & .06 & .08 & .12 & - & & & & & \\
\hline $5 \mathrm{SD}-5$ & $.16^{* *}$ & $.24 * *$ & $.34 * *$ & $.23^{* *}$ & - & & & & \\
\hline $6 \mathrm{MC}-5$ & $.16^{* *}$ & $.25^{* *}$ & $.33^{* *}$ & $.19^{* *}$ & $.57^{* *}$ & - & & & \\
\hline $7 \mathrm{RN}-5$ & $-.18^{* *}$ & $-.15^{*}$ & $-.19^{* *}$ & $-.19^{* *}$ & $-.31^{* *}$ & $-.29 * *$ & - & & \\
\hline $8 \mathrm{VD}-5$ & $.21^{* *}$ & $.33^{* *}$ & $.32 * *$ & .10 & $.34 * *$ & $.41^{* *}$ & $-.24 * *$ & - & \\
\hline $9 \mathrm{CR}-8$ & $.15^{*}$ & $.15^{*}$ & $.22^{* *}$ & $.23^{* *}$ & $.37^{* *}$ & $.30^{* *}$ & $-.41^{* *}$ & $.32^{* *}$ & - \\
\hline $10 \mathrm{RF}-8$ & .08 & $.22^{* *}$ & $.24 * *$ & $.23^{* *}$ & $.36^{* *}$ & $.34 * *$ & $-.43^{* *}$ & $.33^{* *}$ & $.66^{* *}$ \\
\hline \multicolumn{10}{|c|}{ Correlations among age 6 predictors and age 8 literacy skills } \\
\hline 1 Age- 6 & - & & & & & & & & \\
\hline 2 SD-6 & .05 & - & & & & & & & \\
\hline $3 \mathrm{MC}-6$ & $.22^{* *}$ & $.34 * *$ & - & & & & & & \\
\hline $4 \mathrm{RN}-6$ & -.12 & $-.40^{* *}$ & $-.30^{* *}$ & - & & & & & \\
\hline $5 \mathrm{VD}-6$ & $.27^{* *}$ & $.26^{* *}$ & $.43^{* *}$ & $-.13^{*}$ & - & & & & \\
\hline $6 \mathrm{CR}-8$ & $.17^{* *}$ & $.28^{* *}$ & $.27^{* *}$ & $-.42^{* *}$ & $.26^{* *}$ & - & & & \\
\hline $7 \mathrm{RF}-8$ & .10 & $.33^{* *}$ & $.27^{* *}$ & $-.43^{* *}$ & $21^{* *}$ & $.66 * *$ & - & & \\
\hline
\end{tabular}

Note: ${ }^{* *} p<.01, * p<.05 . \mathrm{CA}=$ Compound awareness, GS = Grammatical skill, $\mathrm{NR}=$ Nonword repetition, $\mathrm{SD}=\mathrm{Syllable}$ deletion, $\mathrm{MC}=$ Morphological construction, $\mathrm{RN}=$ Rapid automatized naming, $\mathrm{VD}=$ Vocabulary definition, $\mathrm{CR}=\mathrm{Character}$ recognition, and $\mathrm{RF}=$ Reading fluency. The numbers following each task letter abbreviation refer to the age at which the task was administered. All data are reported for all 261 children except for age 5 rapid naming; since there was one extreme value for this (82.60 seconds), only 260 children's data were calculated on this measure.

group appeared at risk early on in terms of phonological and morphological awareness, as well as maternal education background, but they had no subsequent reading difficulties. The literacy-related cognitive delay (LRC-delay) group showed a pattern that by now appears fairly typical in research on reading disabled Chinese children of having difficulties in phonological awareness, RAN, and morphological awareness (e.g., McBride-Chang et al., 2008; Shu et al., 2006; Wong et al., 2010). Finally, the language-delay group manifested virtually ubiquitous linguistic difficulties from early on and subsequent reading problems.

Previous studies have suggested that languagerelated skills are associated with reading difficulties (Snowling, Gallagher, \& Frith, 2003). As compared to the LRC-delay group, the language-delay group seemed to have more severe problems in reading, at least in fluency skills. This pattern of limited fluency also emerged in a group of Chinese children with initial language delays who, two years later, though diagnosed as free of dyslexia, nevertheless manifested reading skills that were significantly lower than those of a typically developing control group (McBride-Chang et al., in press). The language-delay group was also initially low in nonword repetition, suggesting an association between specific language problems and nonword repetition (Archibald \& Gathercole, 2007; Conti-Ramsden, Botting, \& Faragher, 2001). Collectively, these results suggest that literacy-related cognitive skills are more effective than general language skills in classifying children with reading disabilities in Chinese, as found in previous work on alphabetic orthographies (e.g., Leppänen, Aunola, Niemi, \& Nurmi, 2008; Lyytinen et al., 2006).

Importantly, early prediction of Chinese poor readers should consider a combination of phonological awareness, rapid naming, and morphological awareness. For example, children in the catch-up 
Table 3 Means and standard deviations of different tasks at different ages among the four groups and comparisons across the four groups

\begin{tabular}{|c|c|c|c|c|c|c|c|c|c|c|}
\hline \multirow[b]{2}{*}{ Variable } & \multirow[b]{2}{*}{ Age } & \multicolumn{2}{|c|}{$\begin{array}{l}1 \text { Typical } \\
(N=184)\end{array}$} & \multicolumn{2}{|c|}{$\begin{array}{l}2 \text { Catch-up } \\
(N=31)\end{array}$} & \multicolumn{2}{|c|}{$\begin{array}{l}3 \text { LRC-delay } \\
(N=32)\end{array}$} & \multicolumn{2}{|c|}{$\begin{array}{l}4 \text { Language- } \\
\text { delay } \\
(N=14)\end{array}$} & \multirow[b]{2}{*}{ Comparison } \\
\hline & & M & $\mathrm{SD}$ & M & $\mathrm{SD}$ & M & $\mathrm{SD}$ & M & $\mathrm{SD}$ & \\
\hline \multirow[t]{3}{*}{ Compound awareness } & 3.4 & .01 & .99 & .16 & .95 & .16 & .78 & -.31 & 1.34 & \\
\hline & 4.4 & .05 & .98 & -.18 & 1.15 & -.09 & .93 & -.23 & 1.07 & \\
\hline & 5.4 & .16 & .89 & -.27 & 1.07 & -.52 & 1.04 & .03 & 1.27 & $1>3(F(1,214)=15.25, p<.001)$ \\
\hline \multirow[t]{3}{*}{ Grammatical skills } & 3.4 & .16 & .82 & -.34 & 1.23 & .13 & .67 & -.74 & 1.19 & $\begin{array}{l}1>2(F(1,213)=8.46, p<.01) \\
1>4(F(1,196)=14.58, p<.001)\end{array}$ \\
\hline & 4.4 & .10 & .89 & -.29 & 1.12 & .11 & .89 & -.80 & 1.32 & $1>4(F(1,196)=12.53, p<.001)$ \\
\hline & 5.4 & .13 & .94 & -.24 & .99 & -.53 & 1.06 & -.14 & .91 & $1>3(F(1,214)=13.14, p<.001)$ \\
\hline \multirow[t]{3}{*}{ Nonword repetition } & 3.4 & .12 & .95 & -.15 & .88 & -.06 & .88 & -.85 & .89 & $1>4(F(1,213)=13.40, p<.001)$ \\
\hline & 4.4 & .10 & .95 & -.11 & .93 & -.16 & .93 & -.73 & 1.22 & $1>4(F(1,196)=9.46, p<.01)$ \\
\hline & 5.4 & .07 & .92 & .19 & .83 & -.13 & .92 & -.47 & 1.26 & \\
\hline \multirow[t]{3}{*}{ Syllable deletion } & 4.4 & .39 & .73 & -1.39 & .60 & -.53 & .83 & -1.34 & .57 & $\begin{array}{l}1>2(F(1,213)=165.06, p<.001) \\
1>3(F(1,214)=41.24, p<.001) \\
1>4(F(1,196)=74.64, p<.001)\end{array}$ \\
\hline & 5.4 & .40 & .62 & -.83 & .90 & -.78 & .70 & -1.75 & 1.26 & $\begin{array}{l}1>2(F(1,213)=90.05, p<.001) \\
1>3(F(1,214)=94.52, p<.001) \\
1>4(F(1,196)=128.76, p<.001)\end{array}$ \\
\hline & 6.4 & .44 & .35 & .17 & .45 & -1.09 & .44 & -2.58 & .23 & $\begin{array}{l}1>2(F(1,213)=14.82, p<.001), \\
1>3(F(1,214)=486.34, p<.001), \\
1>4(F(1,196)=1027.08, p<.001)\end{array}$ \\
\hline \multirow[t]{3}{*}{$\begin{array}{l}\text { Morphological } \\
\text { construction }\end{array}$} & 4.4 & .18 & .81 & -.05 & .83 & -.48 & 1.10 & -1.37 & 1.58 & $\begin{array}{l}1>3(F(1,214)=16.07, p<.001) \\
1>4(F(1,196)=40.42, p<.001)\end{array}$ \\
\hline & 5.4 & .18 & .90 & -.36 & .86 & -.39 & .97 & -1.02 & 1.31 & $\begin{array}{l}1>2(F(1,213)=9.76, p<.01) \\
1>3(F(1,214)=10.56, p<.01) \\
1>4(F(1,196)=21.43, p<.001)\end{array}$ \\
\hline & 6.4 & .20 & .97 & -.35 & .84 & -.30 & .82 & -.84 & .93 & $\begin{array}{l}1>2(F(1,213)=8.94, p<.01) \\
1>3(F(1,214)=7.78, p<.001) \\
1>4(F(1,196)=15.02, p<.001)\end{array}$ \\
\hline \multirow[t]{3}{*}{$\begin{array}{l}\text { Rapid automatized } \\
\text { naming }\end{array}$} & 4.4 & .12 & 1.01 & .02 & .74 & -.74 & .59 & -.54 & .89 & $\begin{array}{l}1>3(F(1,214)=20.35, p<.001) \\
1>4(F(1,196)=5.63, p<.05)\end{array}$ \\
\hline & 5.4 & .12 & 1.03 & .00 & .67 & -.49 & .81 & -.81 & .65 & $\begin{array}{l}1>3(F(1,214)=10.17, p<.01) \\
1>4(F(1,196)=11.11, p<.01)\end{array}$ \\
\hline & 6.4 & .14 & 1.00 & .20 & .94 & -.42 & .84 & -.90 & .58 & $\begin{array}{l}1>3(F(1,214)=9.01, p<.01) \\
1>4(F(1,196)=14.97, p<.001)\end{array}$ \\
\hline \multirow[t]{3}{*}{ Vocabulary definitions } & 4.4 & .10 & .99 & -.36 & .97 & -.08 & 1.03 & -.36 & .94 & \\
\hline & 5.4 & .14 & 1.01 & -.27 & .82 & -.12 & .88 & -.88 & .90 & $1>4(F(1,196)=13.45, p<.001)$ \\
\hline & 6.4 & .16 & .92 & -.24 & 1.00 & -.12 & .91 & -.97 & 1.13 & $1>4(F(1,196)=19.15, p<.001)$ \\
\hline Character recognition & 8.4 & .16 & 1.00 & -.27 & .66 & -.35 & .94 & -.63 & 1.10 & $\begin{array}{l}1>3(F(1,214)=7.14, p<.01) \\
1>4(F(1,196)=7.80, p<.01)\end{array}$ \\
\hline Reading fluency & 8.4 & .17 & 1.04 & -.25 & .61 & -.47 & .80 & -.64 & .81 & $\begin{array}{l}1>3(F(1,214)=11.12, p<.01) \\
1>4(F(1,196)=8.18, p<.01)\end{array}$ \\
\hline Nonverbal IQ & 4.4 & 10.49 & 2.63 & 9.97 & 2.02 & 9.75 & 1.88 & 9.50 & 1.79 & $1=2=3=4$ \\
\hline Mother's education level & - & 4.69 & 1.04 & 4.16 & .73 & 4.50 & .80 & 4.00 & 1.11 & $1>2(F(1,213)=7.40, p<.01)$ \\
\hline
\end{tabular}

group showed relatively poor phonological awareness and morphological awareness but average rapid naming performance and subsequently did not manifest reading problems; only the $L R C$-delay and language-delay groups, with difficulties in all three areas, developed reading difficulties, underscoring the idea that Chinese reading difficulties may result from multiple cognitive deficits (e.g., Ho et al., 2004; Shu et al., 2006). The importance of this combination for early identification highlights a fundamental characteristic of Chinese, i.e., that orthography, phonology, and meaning are closely associated here.

Our hypothesis related to parental education level and subsequent reading difficulty was not supported in the present study, however. The mothers of the catch-up group had particularly low educational attainment. Similar to Hecht et al. (2000), we found that one home background variable, mothers' lower educational attainment, was associated with relatively low metalinguistic skills in young children. However, in contrast to their findings, in the present study, these children subsequently caught up to the control group in reading performance. Perhaps this group's adequate performance in language and rapid naming from early on may have facilitated their reading development by age 8 . Another reason for this finding might be that formal school instruction fostered the development of their reading-related cognitive skills, such as phonological awareness, as shown in Figure 2B, and, correspondingly, their subsequent reading skills. Precisely how these 

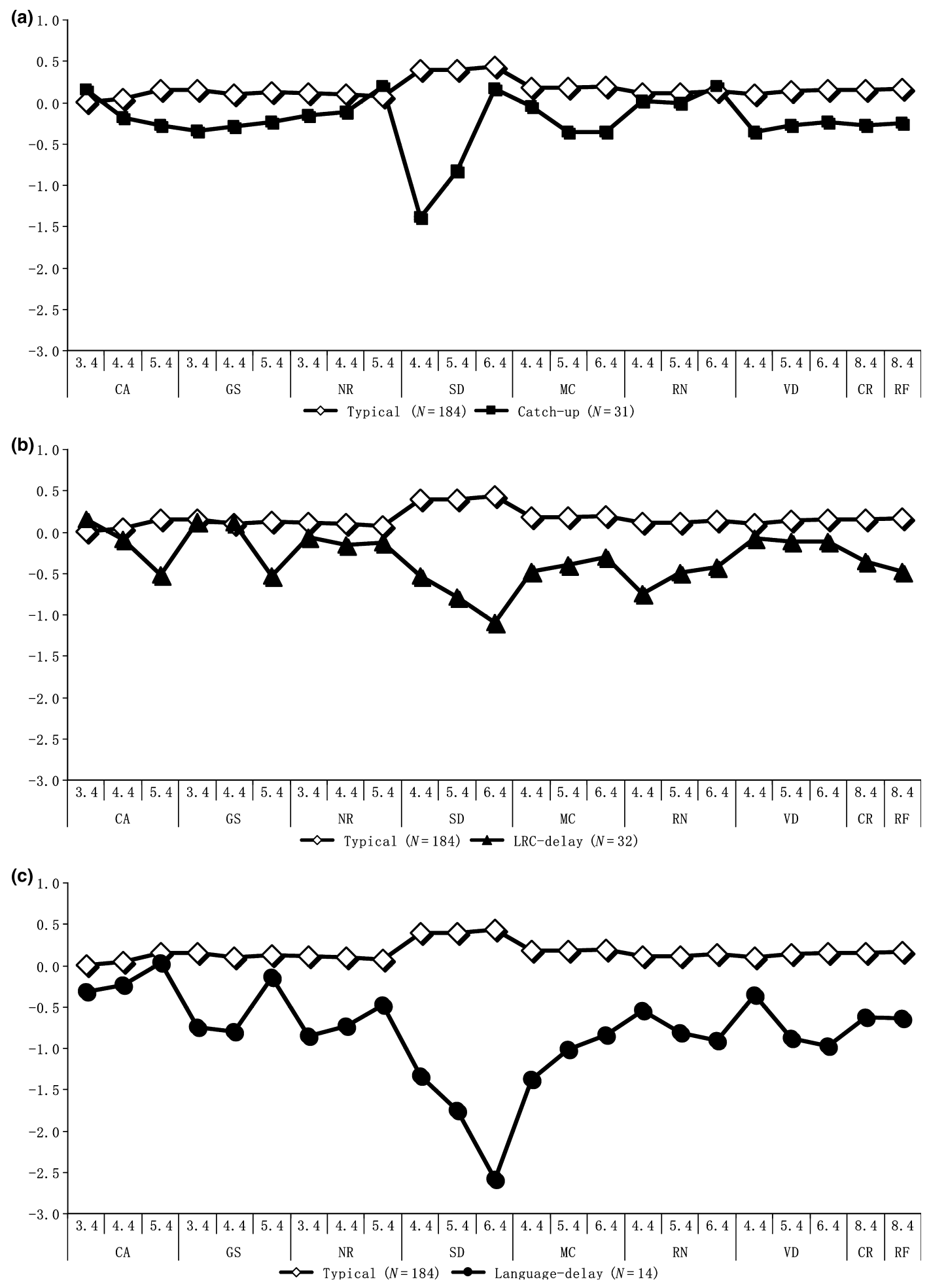

Figure 2 Subgroup members' average performance in the seven skills and in reading. Note: CA-Compound awareness, GS-Grammatical skill, NR-Nonword repetition, SD-Syllable deletion, MC-Morphological construction, RN-Rapid automatized naming, VD-Vocabulary definition, CR-Character recognition, and RF-Reading fluency

children build up strong literacy skills over time is one important question for future research.

Reading development takes place in a given environment, and results of the present study may have been partly affected by specific literacy-related aspects of the Beijing environment that we failed to measure adequately over time, a limitation of the present study. For example, we did not track these children's Pinyin (a phonological coding system based on the Roman alphabet used to teach reading in Mainland China) skills over time. Early Pinyin letter knowledge, though a separate system from Chinese character recognition, might be important for literacy development in these children. In addition, Chinese children's lexical tone awareness may be important for subsequent literacy skills apart 
from those included in the present study (e.g., Shu, Peng, \& McBride-Chang, 2008).

We should be cautious when extending the validity of our results, since our sample was initially selected to be representative of the top, middle, and bottom range of a larger unselected sample, and there were ultimately only 14 children classified in the language-delay trajectory. Nevertheless, the present study was perhaps the most comprehensive exploration of developmental trajectories of reading skills ever carried out in Mainland China, with patterns of reading development and impairment that fit well with previous work on Chinese children.

\section{Conclusion}

The present longitudinal study, spanning six years, identified from a large sample of Chinese children in Beijing one typical and three different atypical developmental trajectories involving early language and cognitive skills in relation to subsequent word reading. The catch-up group read well at age 8, despite initial early deficits in phonological and morphological awareness; maternal education may have played a role in these early difficulties, and good performance in rapid naming may also have facilitated these children's reading development. The literacy-related-cognitive-delay group showed reading problems at age 8 , and the best indicators of subsequent reading difficulty in these children were RAN, phonological awareness, and morphological awareness. The language-delayed group had language difficulties from early on in addition to deficits in RAN, phonological awareness, and morphological awareness; a disproportionate percentage of these children manifested among the most severe reading difficulties in the group. These results highlight the importance of focusing on the combination of phonological awareness, RAN, and morphological awareness from early on in development in order to best identify Chinese children at risk for reading difficulties as well as the risks of early language impairment for subsequent reading disability. Mixed growth modeling is particularly helpful for understanding reading difficulty development over time.

\section{Author note}

Lin Lei and Jinger Pan contributed equally to this work.

\section{Acknowledgements}

This research was supported by the Hong Kong Research Grant Council grant 2120298 in Hong Kong, Program for Changjiang Scholars and Innovative Research Team in University (IRT0710), by US Natural Science Foundation grant BCS\#0350272, and by a grant from the Natural Science Foundation of China (30870758).

\section{Correspondence to}

Hua Shu, State Key Laboratory of Cognitive Neuroscience and Learning, Beijing Normal University, 100875, China; Tel: 86-10-58808186; Fax: 86-1058800567; Email:shuh@bnu.edu.cn

\section{Key points}

- Early prediction of Chinese reading disability should focus on a combination of rapid naming, morphological awareness, and phonological awareness.

- Early language deficits, in addition to a combination of deficits in phonological awareness, morphological awareness, and rapid naming, might lead to more severe reading problems for Chinese children.

- The education level of parents might be an influential factor for final reading outcome, but it is not a strong long-term predictor of reading difficulties as long as a child has adequate reading-related skills, including rapid naming, as well as phonological awareness and morphological awareness abilities.

\section{References}

Archibald, L.M.D., \& Gathercole, S.E. (2007). Nonword repetition in specific language impairment: More than a phonological short-term memory deficit. Psychonomic Bulletin and Review, 14, 919.

Bishop, D.V.M. (1979). Comprehension in developmental language disorders. Developmental Medicine and Child Neurology, 21, 225-238.

Bishop, D.V.M., \& Snowling, M. (2004). Developmental dyslexia and specific language impairment: Same or different? Psychological Bulletin, 130, 858-886.

Bradley, L., \& Bryant, P. (1981). Visual memory and phonological skills in reading and spelling backwardness. Psychological Research, 43, 193-199.
Boscardin, C.K., Muthén, B., Francis, D.J., \& Baker, E.L. (2008). Early identification of reading difficulties using heterogeneous developmental trajectories. Journal of Educational Psychology, 100, 192.

Chen, X., Hao, M., Geva, E., Zhu, H., \& Shu, H. (2009). The role of compound awareness in Chinese children's vocabulary acquisition and character reading. Reading and Writing, 22, 615-631.

Chung, K.H., McBride-Chang, C., Wong, S.W.L., Cheung, H., Penney, T.B., \& Ho, C.S.-H. (2008). The role of visual and auditory temporal processing for Chinese children with developmental dyslexia. Annals of Dyslexia, 58, $15-35$.

Conti-Ramsden, G., Botting, N., \& Faragher, B. (2001). Psycholinguistic markers for specific language 
impairment (SLI). Journal of Child Psychology and Psychiatry, 42, 741-748.

Gabrieli, J.D.E. (2009). Dyslexia: A new synergy between education and cognitive neuroscience. Science, 325, 280-283.

Hecht, S.A., Burgess, S.R., Torgesen, J.K., Wagner, R.K., \& Rashotte, C.A. (2000). Explaining social class differences in growth of reading skills from beginning kindergarten through fourth-grade: The role of phonological awareness, rate of access, and print knowledge. Reading and Writing, 12, 99-128.

Ho, C.S.-H., Chan, D.W.-O., Lee, S.-H., Tsang, S.-M., \& Luan, V. H. (2004). Cognitive profiling and preliminary subtyping in Chinese developmental dyslexia. Cognition, 91, 43-75.

Leppänen, U., Aunola, K., Niemi, P., \& Nurmi, J.E. (2008). Letter knowledge predicts Grade 4 reading fluency and reading comprehension. Learning and Instruction, 18, 548-564.

Leppänen, U., Niemi, P., Aunola, K., \& Nurmi, J.E. (2004). Development of reading skills among preschool and primary school pupils. Reading Research Quarterly, 39(1), 72-93.

Liu, P.D., McBride-Chang, C., Wong, A.M.-Y., Tardif, T., Stokes, S., Fletcher, P., \& Shu, H. (2010). Early oral language markers of poor reading performance in Hong Kong Chinese children. Journal of Learning Disabilities, 43, 322-331.

Lyytinen, H., Erskine, J., Tolvanen, A., Torppa, M., Poikkeus, A.M., \& Lyytinen, P. (2006). Trajectories of reading development: A follow-up from birth to school age of children with and without risk for dyslexia. MerrillPalmer Quarterly, 52, 514-546.

McBride-Chang, C., Lam, F., Lam, C., Chan, B., Fong, C.Y.-C., Wong, T.T.-Y., \& Wong, S.W.-L. (in press). Early predictors of dyslexia in Chinese children: Familial history of dyslexia, language delay, and cognitive profiles. Journal of Child Psychology and Psychiatry.

McBride-Chang, C., Shu, H., Zhou, A., Wat, C.P., \& Wagner, R.K. (2003). Morphological awareness uniquely predicts young children's Chinese character recognition. Journal of Educational Psychology, 95, 743-751.

McBride-Chang, C., Tardif, T., Cho, J.-R., Shu, H., Fletcher, P., Stokes, S., Wong, A., \& Leung, K. (2008). What's a word? Morphological awareness and vocabulary knowledge in three languages. Applied Psycholinguistics, 29, 437-462.

Moll, K., Fussenegger, B., Willburger, E., \& Landerl, K. (2009). RAN is not a measure of orthographic processing. Evidence from the asymmetric German orthography. Scientific Studies of Reading, 13, 1-25.

Muthén, B. (2001). Second-generation structural equation modeling with a combination of categorical and continuous latent variables: New opportunities for latent class / latent growth modeling. In L.M. Collins, \& A. Sayer (Eds.), New methods for the analysis of change (pp. 289322). Washington, DC: American Psychological Association.

Muthén, L.K., \& Muthén, B.O. (2004). Mplus user's guide. Los Angeles: Author.

Rauh, V.A., Parker, F.L., Garfinkel, R.S., Perry, J., \& Andrews, H.F. (2003). Biological, social, and community influences on third-grade reading levels of minority Head Start children: A multilevel approach. Journal of Community Psychology, 31, 255-278.

Raven, J.C., Court, J.H., \& Raven, J. (1996). Standard progressive matrices. Oxford: Oxford Psychologists Press.
Scarborough, H.S., \& Parker, J.D. (2003). Matthew effects in children with learning disabilities: Development of reading, IQ, and psychosocial problems from grade 2 to grade 8. Annals of Dyslexia, 53, 47-71.

Shu, H., Chen, X., Anderson, R.C., Wu, N., \& Xuan, Y. (2003). Properties of school Chinese: Implications for learning to read. Child Development, 74, 27-47.

Shu, H., McBride-Chang, C., Wu, S., \& Liu, H. (2006). Understanding Chinese developmental dyslexia: Morphological awareness as a core cognitive construct. Journal of Educational Psychology, 98, 122-133.

Shu, H., Peng, H., \& McBride-Chang, C. (2008). Phonological awareness in young Chinese children. Developmental Science, 11, 171-178.

Siegel, L., \& Ryan, E. (1989). The development of working memory in normally achieving and subtypes of learning disabled children. Child Development, 60, 973-980.

Snowling, M.J., Gallagher, A., \& Frith, U. (2003). Family risk of dyslexia is continuous: Individual differences in the precursors of reading skill. Child Development, 74, 358-373.

Stokes, S.F., Wong, A.M.-Y., Fletcher, P., \& Leonard, L.B. (2006). Nonword repetition and sentence repetition as clinical markers of specific language impairment: The case of Cantonese. Journal of Speech, Language, and Hearing Research, 49, 219-236.

Tager-Flusberg, H., \& Cooper, J. (1999). Present and future possibilities for defining a phenotype for specific language impairment. Journal of Speech, Language, and Hearing Research, 42, 1275-1278.

Tardif, T., Fletcher, P., Zhang, Z.X., \& Liang, W.L. (2008). The Chinese Communicative Development Inventory (Putonghua and Cantonese versions): Manual, forms, and norms. Beijing: Peking University Medical Press.

Thorndike, R.L., Hagen, E.P., \& Sattler, J.M. (1986). The Stanford-Binet intelligence scale: Fourth Edition guide for administrating and scoring. Chicago, IL: Riverside.

Torgesen, J.K., Wagner, R.K., Rashotte, C.A., Burgess, S., $\&$ Hecht, S. (1997). Contributions of phonological awareness and rapid automatic naming ability to the growth of word-reading skills in second- to fifth-grade children. Scientific Studies of Reading, 1, 161-185.

Vaessen, A., Gerretsen, P., \& Blomert, L. (2009). Naming problems do not reflect a second independent core deficit in dyslexia: Double deficits explored. Journal of Experimental Child Psychology, 103, 202-221.

Viholainen, H., Ahonen, T., Lyytinen, P., Cantell, M., Tolvanen, A., \& Lyytinen, H. (2006). Early motor development and later language and reading skills in children at risk of familial dyslexia. Developmental Medicine and Child Neurology, 48, 367-373.

Wong, A.M.-Y., Kidd, J., Ho, C.S.-H., \& Au, T.K.-F. (2010). Characterizing the overlap between SLI and dyslexia in Chinese: The role of phonology and beyond. Scientific Studies of Reading, 14, 30-57.

Zhou, X., Chen, Y., Chen, C., Jiang, T., Zhang, H., \& Dong, Q. (2007). Chinese kindergartners' automatic processing of numerical magnitude in Stroop-like tasks. Memory and Cognition, 35, 464-470.

Ziegler, J., Bertrand, D., Tóth, D., Csépe, V., Reis, A., Faísca, L., Saine, N., Lyytinen, H., Vaessen, A., \& Blomert, L. (2010). Orthographic depth and its impact on universal predictors of reading: A cross-language investigation. Psychological Science, 21, 551-559.

Manuscript accepted 1 July 2010 